Article

\title{
Binder-Free Electrode Based on ZnO Nanorods Directly Grown on Aluminum Substrate for High Performance Supercapacitors
}

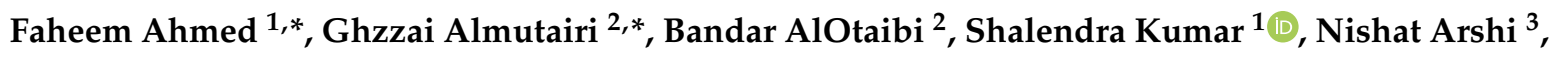 \\ Syed Ghazanfar Hussain ${ }^{1, *}$, Ahmad Umar ${ }^{4,5}$, Naushad Ahmad ${ }^{6}$ and Abdullah Aljaafari ${ }^{1}$ (D) \\ 1 Department of Physics, College of Science, King Faisal University, P.O. Box-400, \\ Al-Ahsa 31982, Saudi Arabia; sjagdish@kfu.edu.sa (S.K.); aaljaafari@kfu.edu.sa (A.A.) \\ 2 National Center for Energy Storage Technologies, King Abdulaziz City for Science and Technology (KACST), \\ Riyadh 12354, Saudi Arabia; bmalotaibi@kacst.edu.sa \\ 3 Department of Basic Sciences, Preparatory Year Deanship, King Faisal University, \\ Al-Ahsa 31982, Saudi Arabia; nshastri@kfu.edu.sa \\ 4 Department of Chemistry, Faculty of Science and Arts, NajranUniversity, Najran 11001, Saudi Arabia; \\ ahmadumar786@gmail.com \\ 5 Promising Centre for Sensors and Electronic Devices (PCSED), Najran University, Najran 11001, Saudi Arabia \\ 6 Department of Chemistry, College of Science, King Saud University, Riyadh 11451, Saudi Arabia; \\ anaushad@ksu.edu.sa \\ * Correspondence: fahmed@kfu.edu.sa (F.A.); gmotari@kacst.edu.sa (G.A.); sghazanfar@kfu.edu.sa (S.G.H.); \\ Tel./Fax: +966-013589-6900 (F.A.)
}

Received: 10 August 2020; Accepted: 28 September 2020; Published: 7 October 2020

check for updates

\begin{abstract}
Herein, for the first time, the growth of $\mathrm{ZnO}$ nanorods directly on aluminum (Al) substrate via a low temperature $\left(80^{\circ} \mathrm{C}\right)$ wet chemical method, and used as binder-free electrode for supercapacitors were reported. XRD pattern and HRTEM images showed that high crystalline nanorods grown on $\mathrm{Al}$ substrate with c-axis orientation. Morphological studies revealed that the nanorods possessed well defined hexagon phase with length and diameter of $\sim 2 \mu \mathrm{m}$ and 100-180 nm, respectively. Raman spectrum of $\mathrm{ZnO}$ nanorods showed that the characteristic $\mathrm{E}_{2 \mathrm{H}}$ mode corresponds to the vibration associated with the oxygen atoms of $\mathrm{ZnO}$. The optical properties of $\mathrm{ZnO}$ nanorods studied using Room-temperature PL spectra revealed a near-band-edge (NBE) peak at $\sim 388 \mathrm{~nm}$ emission and deep level (DLE) at $~ 507 \mathrm{~nm}$. Electrochemical measurements showed that $\mathrm{ZnO}$ nanorods on $\mathrm{Al}$ substrate exhibited remarkably enhanced performance as electrode for supercapacitors with a value of specific capacitance of $394 \mathrm{~F} \mathrm{~g}^{-1}$ measured with scan rate of $20 \mathrm{mV} \mathrm{s}^{-1}$. This unique nanorods structures also exhibited excellent stability of $>98 \%$ capacitance retention for 1000 cycles that were measured at $1 \mathrm{~A} \mathrm{~g}^{-1}$. The presented easy and cost-effective method might open up the possibility for the mass production of binder-free electrodes for efficient electrochemical energy storage devices.
\end{abstract}

Keywords: $\mathrm{ZnO}$; binder-free electrode; X-ray diffraction; supercapacitors; nanorods

\section{Introduction}

In recent years, among the different energy storage systems, supercapacitors have gained the significant interest of researchers and scientific community due to their superior power density, longer life cycle, and cost effective maintenance as compared with the batteries/fuel cells, while it showed better energy density than conventional capacitors [1,2]. These supercapacitors have been potentially used in various applications, including hybrid electric vehicles, solar power plants, and portable consumer electronics [3,4]. Furthermore, the utilization of cost-effective and non-toxic electrode 
materials used in supercapacitors made them a suitable choice for consumers with environmentally friendly features [3-8]. Ideal capacitive materials, such as carbon nanostructure, have shown promising results with excellent cycle life. In a report, Xiao et al. [9] inserted nitrogen into graphene using nitric acid through thermal treatment at $500{ }^{\circ} \mathrm{C}$, which showed a capacitance value of $370 \mathrm{~F} \mathrm{~g}^{-1}$ at $1 \mathrm{~A} \mathrm{~g}^{-1}$ in $6 \mathrm{M} \mathrm{NaOH}$. On the other hand, in general, a pseudocapacitor consists of a transition metal oxide, including $\mathrm{RuO}_{2}$ [10], $\mathrm{MnO}_{2}$ [11], $\mathrm{V}_{2} \mathrm{O}_{5}$ [12], or $\mathrm{ZnO}$ [13]. These oxides contain different valence states in which the charges can be stored either by physical adsorption or by performing reversible faradic charge-transfer reaction taking place on the surface of electrode. Thus, their relatively fast and reversible faradic redox reactions made the pseudocapacitor a promising device with high power and high energy density. Among the above-mentioned metal oxides, due to its excellent features of high quasi-metallic conductivity and high capacitance, $\mathrm{RuO}_{2}$ has attracted enormous interest as a suitable material for electrode [14]. Although, high cost, limited availability, and the environmental safety problems make this material unsuitable. Therefore, inexpensive transition metal oxides materials based electrodes with high energy density as a possible substitute for $\mathrm{RuO}_{2}$ are needed.

Recently, Zinc oxide ( $\mathrm{ZnO}$ ) with direct bandgap energy of $3.37 \mathrm{eV}$ has been gained enormous interestdue to cost effectiveness and excellent electrochemical properties $[15,16]$. Several reports have been presented on $\mathrm{ZnO}$ based electrodes as a suitable candidate for supercapacitor. Chen et al. showed that $\mathrm{ZnO}$ nanorods coated with $\mathrm{MnO}_{2}$ resulted to a specific capacitance value of $222 \mathrm{~F} \mathrm{~g}^{-1}$ at $25 \mathrm{mV} \mathrm{s}^{-1}$ [17]. A value of specific capacitance of $62.2 \mathrm{~F} \mathrm{~g}^{-1}$ obtained at $0.5 \mathrm{Ag}^{-1} \mathrm{had}_{\text {been reported }}$ for $\mathrm{ZnO} /$ graphene nanosheets [18]. In another work, $\mathrm{A} \mathrm{ZnO} /$ graphene nanocomposites that were synthesized by using microwave methods showed a value of specific capacitance of $146 \mathrm{~F} \mathrm{~g}^{-1}$ [19]. In case of carbon nanotube-ZnO nanocomposites electrodes, Zhang et al. [20] reported a maximum specific capacitance of $323.9 \mathrm{~F} \mathrm{~g}^{-1}$. On the other hand, graphene- $\mathrm{ZnO}$ composite films exhibited a specific capacitance of $11.3 \mathrm{~F} \mathrm{~g}^{-1}$ [21]. A composite containing $\mathrm{ZnO} / \mathrm{carbon}$ that was reported by Jayalakshmi et al. [22] demonstrated a value of specific capacitance of $21.7 \mathrm{~F} \mathrm{~g}^{-1}$. In another report, composite electrodes containing activated carbon nanofiber and $\mathrm{ZnO}$ that was prepared by Kim et al. [23] reported a specific capacitance of $178.2 \mathrm{~F} \mathrm{~g}^{-1}$. It is clear that all of these works mentioned above were mainly focused on $\mathrm{ZnO}$ based composites for supercapacitors. However, less attention has been given on the use of $\mathrm{ZnO}$ as an electrode material, thus there is a lack of research reported on $\mathrm{ZnO}$ for supercapacitors. He et al. [24] demonstrated the growth of $\mathrm{ZnO}$ nanocones that were obtained by chemically etching $\mathrm{ZnO}$ nanowires (NWs) and obtained a value of $378.5 \mathrm{~F} \mathrm{~g}^{-1}$ for $\mathrm{ZnO}$ nanocones and $191.5 \mathrm{~F} \mathrm{~g}^{-1}$ for $\mathrm{ZnO}$ NWs, respectively. In another work [25], ZnO particles that were prepared by hydrothermal method with various precursors nitrate, acetate and chloride produced specific capacitance of $5.87 \mathrm{~F} \mathrm{~g}^{-1}, 5.35 \mathrm{~F} \mathrm{~g}^{-1}$, and $4.14 \mathrm{~F} \mathrm{~g}^{-1}$, respectively. In recent work, Luo et al. [26] showed maximum capacitance value of $160.4 \mathrm{~F} \mathrm{~g}^{-1}$ for the electrodes that were based on $\mathrm{ZnO}$ tetrapods structures. Though the nanocomposites of $\mathrm{ZnO}$ and $\mathrm{ZnO}$ alone have been demonstrated to exhibit a comparable specific capacitance value [17-26], during charge and discharge cycling, a loosely adhered layer on the current collector might be risky and detached from the surface, leading to the poor performance of $\mathrm{ZnO}$ electrodes [27-29].

Therefore, the key solution for these problems is the development of nanostructured $\mathrm{ZnO}$ by facile synthesis methods. To achieve this target, the growth of nanostructures including nanorods, nanowires, and nanotubes directly on conductive substrates could be considered. Particularly, conductive substrate based electrodes provide excellent electrical contacts, which helps in achieving high electrochemical performance by comparing with the powder electrodes that were coated by a common slurry pasting method [30,31].

Until now, $\mathrm{ZnO}$ nanorods grow directly on the conductive substrates and are used as binder-free electrode for supercapacitors has not yet been reported. In this work, we have demonstrated, for the very first time, a facile and versatile strategy for the growth of $\mathrm{ZnO}$ nanorods vertically on $\mathrm{Al}$ substrate by using low temperature $\left(80^{\circ} \mathrm{C}\right)$ wet chemical method for asymmetrical supercapacitors containing a binder-free electrode. The wet chemical method has the advantage of low operating temperatures 
(below $100{ }^{\circ} \mathrm{C}$ ), and rapid and low process costs. Electrochemical studies of the $\mathrm{ZnO}$ nanorods electrode demonstrated a high value of specific capacitance of $394 \mathrm{~F} \mathrm{~g}^{-1}$ at a scan rate of $20 \mathrm{mV} \mathrm{s}^{-1}$, and excellent stability of $>98 \%$ capacitance maintained even after 1000 cycles at $1 \mathrm{~A} \mathrm{~g}^{-1}$. The presented approach for the growth of $\mathrm{ZnO}$ nanostructures might provide a path for the preparation of cost effective binder-free electrode.

\section{Experimental Details}

$\mathrm{ZnO}$ nanorods with high crystalline nature were grown on $\mathrm{Al}$ substrate $(15 \mu \mathrm{M}$ thick sheets; MTI, Richmond, CA, USA) that was seeded with $\mathrm{ZnO}$ particles. The Al foil was pre-treated prior to the seeding step. The foil was washed by acetone $(99.99 \%)$, ethanol $(99.99 \%)$, and distilled water) sequentially. After the cleaning, foil was dried in an oven at $80{ }^{\circ} \mathrm{C}$. The dried $\mathrm{Al}$ foil was then used for seeding. The fabrication of $\mathrm{ZnO}$ nanorods was performed in two steps. The first step was performed to deposit a seed layer with spin coating using $\mathrm{ZnO}$ solution containing a mixture of $30 \mathrm{mM} \mathrm{NaOH}$ and $10 \mathrm{mM}$ zinc acetate solution in ethanol, followed by heating at $200{ }^{\circ} \mathrm{C}$ for $5 \mathrm{~min}$. The second step resulted in $\mathrm{ZnO}$ nanorods growth and was carried out by using the wet chemical method. An equimolar $(10 \mathrm{mM})$ aqueous solution of hexamethylenetetramine (HMT) $\left(\mathrm{C}_{6} \mathrm{H}_{12} \mathrm{~N}_{4} ; 99.99 \%\right.$, Sigma Aldrich) and zinc nitrate $\left(\mathrm{Zn}(\mathrm{NO})_{3} \cdot 6 \mathrm{H}_{2} \mathrm{O} ; 99.99 \%\right.$, Sigma Aldrich, St. Louis, MO, USA) was prepared for the growth. For the synthesis, HMT solution was preheated at $80{ }^{\circ} \mathrm{C}$, in which zinc nitrate solution was mixed, and then $\mathrm{Al}$ substrate was put into the solution in seed facing down position. This reaction was carried on for $1 \mathrm{~h}$, and vertically aligned $\mathrm{ZnO}$ nanorods on $\mathrm{Al}$ substrate were grown. Lastly, the washing of as grown $\mathrm{ZnO}$ nanorods was performed numerous times in deionized water, followed by drying at $80^{\circ} \mathrm{C}$ for $12 \mathrm{~h}$. Figure 1 demonstrates a schematic drawing of the $\mathrm{ZnO}$ nanorods growth on $\mathrm{Al}$ substrate.

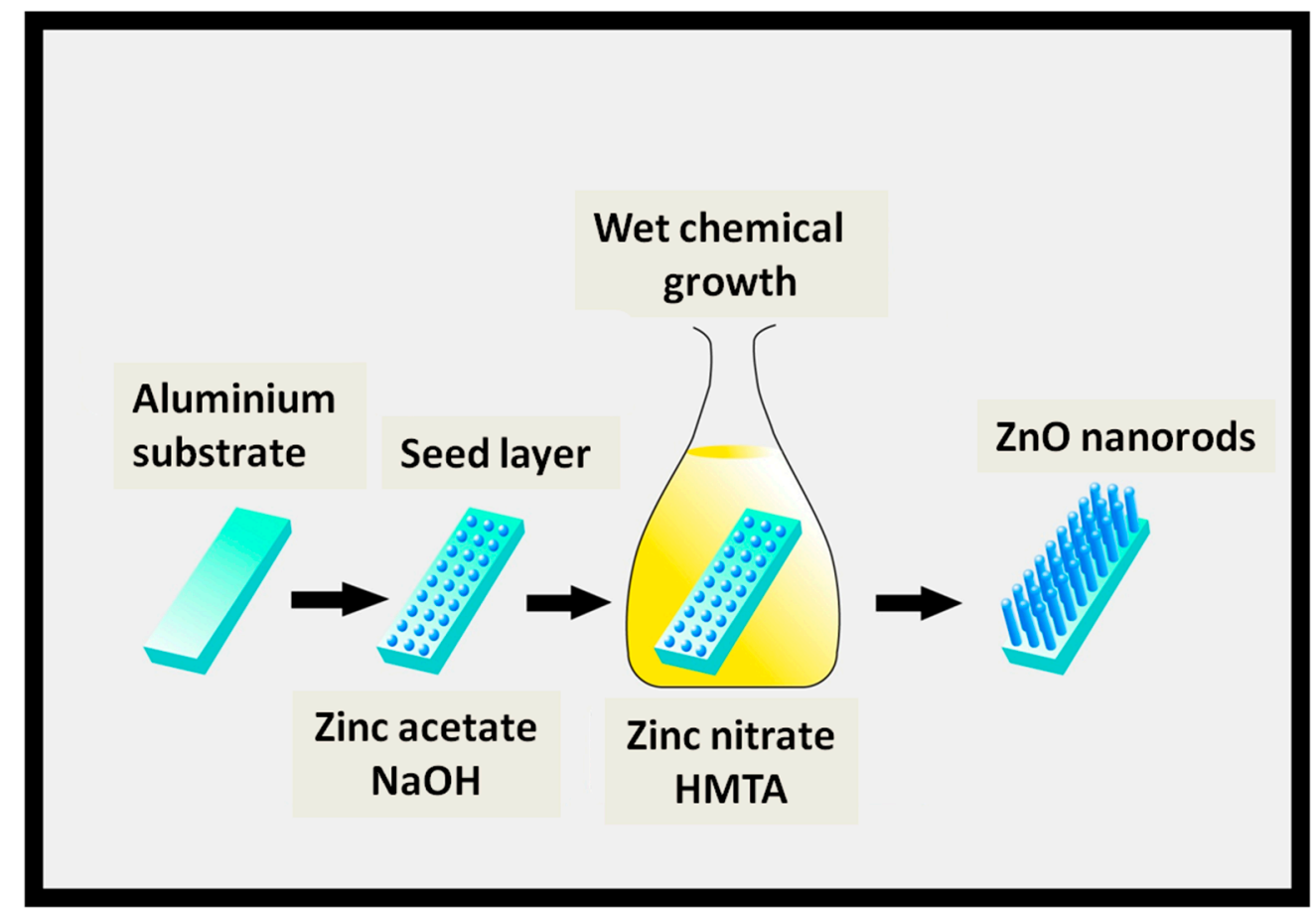

Figure 1. A Schematic diagram for the growth of $\mathrm{ZnO}$ nanorods on $\mathrm{Al}$ substrate.

The structural information of the product was obtained using X-ray diffractometer (Phillips X'pert; MPD 3040, EA Almelo, The Netherlands) that was equipped with $\mathrm{Cu} \mathrm{K} \alpha$ radiations. Morphological studies of the product were carried out by using field-emission scanning electron microscope (FE-SEM, TESCAN, MIRA II LMH, Brno-Kohoutovice, Czech Republic) and transmission electron microscope (TEM; JEOL 2100, Corporation Place, Singapore). To obtain further structural information of ZnO nanorods, Raman spectrum was recorded with the help of Raman spectrophotometer (NRS-3100, 
JASCO, MD, USA) with a wavelength of $532 \mathrm{~nm}$. In order to perform optical characterization of $\mathrm{ZnO}$ nanorods, a Photo-luminescence (PL) spectrometer (JASCO, FP-6500, MD, USA) was used at room temperature. Electrochemical measurements of the $\mathrm{ZnO}$ nanorods were performed using three electrode cells by an electrochemical analyzer system (Gamry 600, PA, USA). For the working electrode, binder-free $\mathrm{ZnO}$ nanorods on $\mathrm{Al}$ substrate were used. All of the electrochemical studies were carried out in $2 \mathrm{M} \mathrm{KOH}$ with a counter electrode of a Pt wire and $\mathrm{Ag} / \mathrm{AgCl}$ served for the reference electrode. A potential range of -1.6 to $1.0 \mathrm{~V}$ was used for the cyclic voltammetry (CV) studies, while Charge-discharge (CD) studies were conducted over 0 to $1.0 \mathrm{~V}$. For the calculation of specific capacitance using the $\mathrm{CV}$ and $\mathrm{CD}$ method, the following equations have been used [32]:

$$
\begin{gathered}
C=\frac{1}{2 m V k} \int_{V^{-}}^{V^{+}} I(V) d V \quad \text { By CV } \\
C=\frac{I \times \Delta t}{V \times m} \quad \text { By CD }
\end{gathered}
$$

where $C\left(\mathrm{~F} \mathrm{~g}^{-1}\right)$ defines the specific capacitance, $I(\mathrm{~A})$ represents discharge current, $\Delta t(\mathrm{~s})$ is discharge time, while $V(\mathrm{~V})$ corresponds to the potential range, $m(\mathrm{~g})$ represents the mass used of the active material, and $k\left(\mathrm{~V} \mathrm{~s}^{-1}\right)$ is scan rate. A frequency that ranges from $1 \mathrm{~Hz}-100 \mathrm{kHz}$ was used for the electrochemical impedance spectroscopy (EIS) analysis.

\section{Results and Discussion}

Figure 2 depicts the $\mathrm{XRD}$ patterns of $\mathrm{ZnO}$ nanorods grown vertically on $\mathrm{Al}$ substrate. Various researchers have used $\mathrm{Al}_{2} \mathrm{O}_{3}$ substrate to grow $\mathrm{ZnO}$ nanorods. You et al. [33] reported the growth of $\mathrm{ZnO}$ and $\mathrm{ZnMgO}$ films on $\mathrm{Al}_{2} \mathrm{O}_{3}$ (001) substrate. They have shown that besides the sapphire substrate diffraction peak located at $41.7^{\circ}$, only (002) and (004) diffraction peaks of $\mathrm{ZnO}$ at about $34.3^{\circ}$ and $72.4^{\circ}$ are observed for the $\mathrm{ZnO}$ film, which indicated that the $\mathrm{ZnO}$ thin film was grown along a c-axis orientation of the sapphire substrate. Their XRD results indicated that, due to the preferred single orientation (001) of the $\mathrm{Al}_{2} \mathrm{O}_{3}$ substrate, only peaks that are parallel to (001) planes of $\mathrm{ZnO}$ are observed in the XRD pattern. While, no other peaks that belong to $\mathrm{ZnO}$ can be seen in the XRD pattern. The similar behavior was also observed in another report that was presented by Yang et al. [34] on the growth of $\mathrm{ZnO}$ thin films on sapphire (001) substrates. They showed that only two peaks thatcontributed to the (002) and (004) planes of $\mathrm{ZnO}$ were observed. No other peaks were detected within the detection limit of $\mathrm{XRD}$, which conclude that $\mathrm{ZnO}$ grown on $\mathrm{Al}_{2} \mathrm{O}_{3}$ (001) substrate results in the growth of $\mathrm{ZnO}$ along (001) parallel planes only. However, in our work, we have used $\mathrm{Al}$ substrate for the growth of $\mathrm{ZnO}$ nanorods. Figure S1 shows the XRD pattern of Al substrate used in our work. The diffraction peaks observed at $2 \theta$ values of 38.28, 44.59, and 64.91 correspond to the (111), (200), and (220) planes of the bare Al substrate (JCPDF card \# 85-1327) [35]. All the peaks in our XRD pattern (Figure 2) are indexed to wurtzite $\mathrm{ZnO}$ structure, and in close agreement with the standard data of JCPDS 89-1397. Among all of the planes of ZnO in the XRD patterns, the intensity of (002) plane is extremely high, which clearly reveals that the $\mathrm{ZnO}$ nanorods possess single-phase with high crystallinity and grow along the c-axis. There are other peaks present that correspond to $\mathrm{ZnO}$ with less intensity than that of (002) plane of $\mathrm{ZnO}$. However, the peak related to $\mathrm{Al}$ was not observed within the detection limit of $\mathrm{XRD}$, it might be due to very high intensity of (002) peaks of $\mathrm{ZnO}$, which suppressed other peaks either related to $\mathrm{Al}$ or $\mathrm{ZnO}$. Therefore, it is clear that we have used $\mathrm{Al}$ substrate for the growth of $\mathrm{ZnO}$ nanorods and $\mathrm{Al}_{2} \mathrm{O}_{3}$ was not used. If $\mathrm{Al}_{2} \mathrm{O}_{3}$ substrate was used in our work, the $\mathrm{XRD}$ pattern must have shown only peaks parallel to (001) plane of $\mathrm{ZnO}$ along with (006) peak of $\mathrm{Al}_{2} \mathrm{O}_{3}$ substrate, as reported in previous work, but this is not the case in our XRD results. Thus, the possibility of the use of $\mathrm{Al}_{2} \mathrm{O}_{3}$ substrate in this work has been ruled out. Table $\mathrm{S} 1$ summarizes the discussion. 


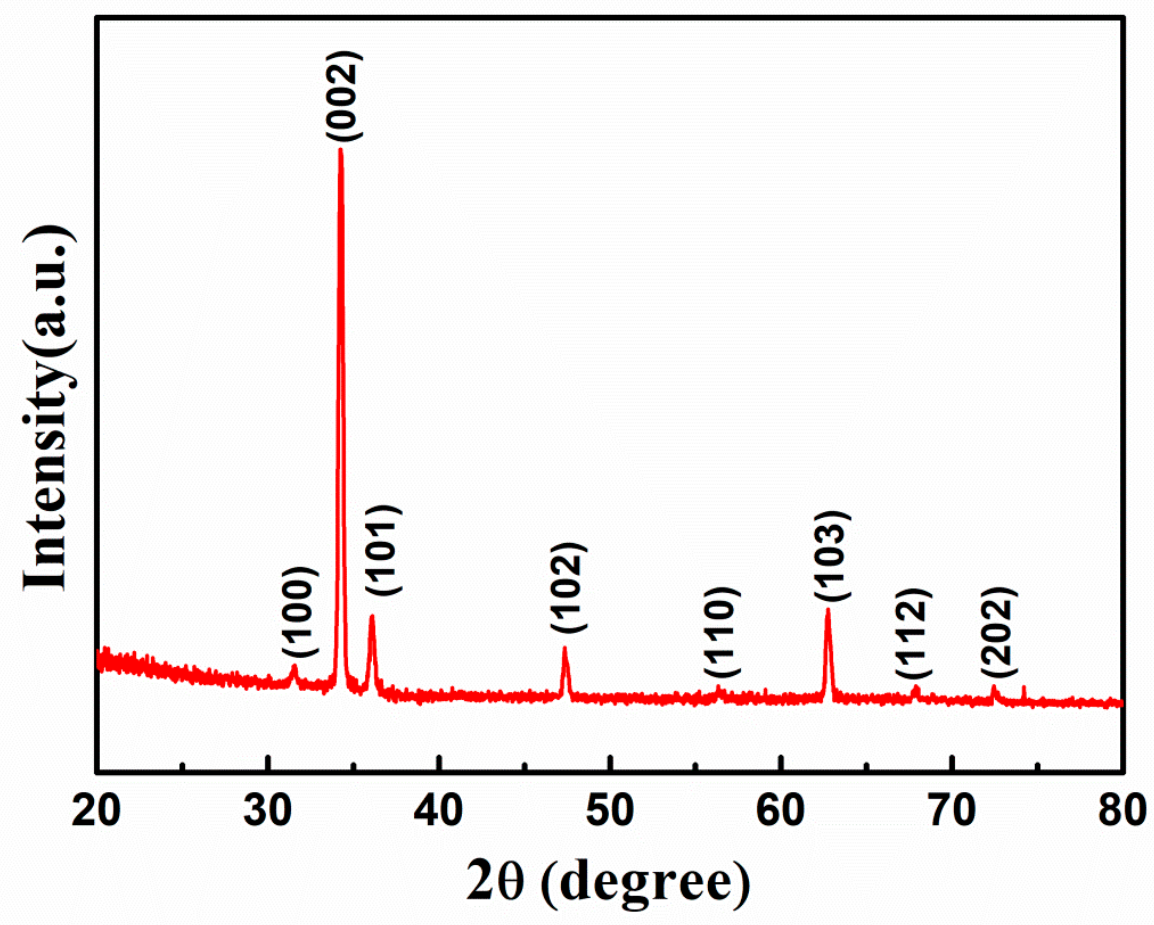

Figure 2. XRD patterns of $\mathrm{ZnO}$ nanorods grown on $\mathrm{Al}$ substrate.

Morphological studies of the as-grown $\mathrm{ZnO}$ nanorods were performed by FESEM and TEM techniques and are shown in Figure 3. Figure 3a shows the FESEM micrographs of vertically aligned $\mathrm{ZnO}$ nanorods that were grown on $\mathrm{Al}$ substrate synthesized at $80{ }^{\circ} \mathrm{C}$. The overall morphological features of the $\mathrm{ZnO}$ nanorods could be evidently seen and revealed the formation of clear nanorods. The inset of Figure 3a shows that each individual $\mathrm{ZnO}$ nanorod consists of a well-defined hexagon facet. The nanorods have length and diameter of $\sim 2 \mu \mathrm{m}$ and 100-180 $\mathrm{mm}$, respectively, and the size distribution is homogenous throughout the surface of Al substrate. The homogeneity of such nanostructures is helpful in achieving high energy density by facilitating the charge transport during charge and discharge $[29,36]$. Additionally, a good electrical contact could be assured with the unique design of the electrode with such morphology on Al current collector/substrate; as a result, the area of interaction on the electrode/electrolyte interface might increase.
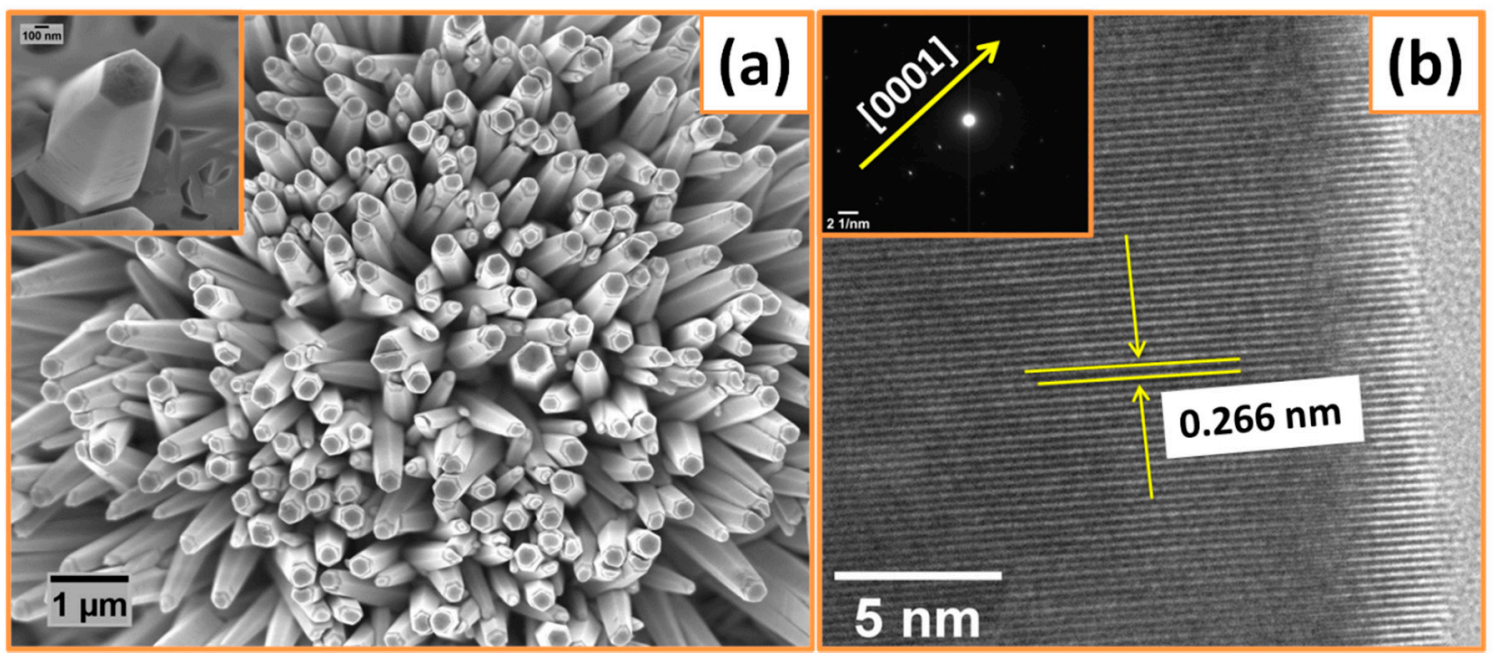

Figure 3. (a) Field-emission scanning electron microscope (FE-SEM) image of ZnO nanorods, inset shows a single nanorod. (b) HRTEM image, and inset shows the SAED pattern of ZnO nanorods. 
Additional morphological features and crystalline quality of $\mathrm{ZnO}$ nanorods were achieved through TEM investigations. The atomic structure related information obtained from HRTEM image in Figure 3b depicts the highly crystalline nature of $\mathrm{ZnO}$ nanorods with interlayer spacing of $0.266 \mathrm{~nm}$, which attributes to the d spacing of (002) lattice plane in $\mathrm{ZnO}$ structures. The results that were obtained from HRTEM further confirm the XRD studies where the $\mathrm{ZnO}$ nanorods have preferred growth direction along $c$-axis. The inset of Figure $3 b$ shows the SAED patterns of the nanorods containing bright dot patterns that correspond to single-crystal behavior of as-prepared $\mathrm{ZnO}$ nanorods.

Raman spectroscopy was performed at room temperature in order to study the defects and crystal structure of $\mathrm{ZnO}$ nanorods. Generally, $\mathrm{ZnO}$ with a space group of $\mathrm{C}_{6}^{4} 6 \mathrm{~V}$ and wurtzite structure contains two formula units in a primitive cell [37]. The origin of Raman active modes in the spectra are usually governed by various symmetries, and the frequency of vibrations might shift due to the change in chemical surroundings and spacing between lattices [38]. Figure 4 shows room temperature Raman plot of $\mathrm{ZnO}$ nanorods with the peaks positioned at $332 \mathrm{~cm}^{-1}, 435 \mathrm{~cm}^{-1}$, and $581 \mathrm{~cm}^{-1}$. The peak at $435 \mathrm{~cm}^{-1}$ corresponds to the characteristics $\mathrm{E}_{2 \mathrm{H}}$ mode of $\mathrm{ZnO}$ wurtzite structure. The peaks that were observed at $332 \mathrm{~cm}^{-1}$ and $581 \mathrm{~cm}^{-1}$ belong to the Raman $\mathrm{E}_{2 \mathrm{H}}-\mathrm{E}_{2 \mathrm{~L}}$ and $\mathrm{E}_{1 \mathrm{~L}}$ mode, respectively, of $\mathrm{ZnO}$. The high intensity of $\mathrm{E}_{2 \mathrm{H}}$ mode as compared to other modes further reveals the $c$-axis orientation of $\mathrm{ZnO}$ nanorods.

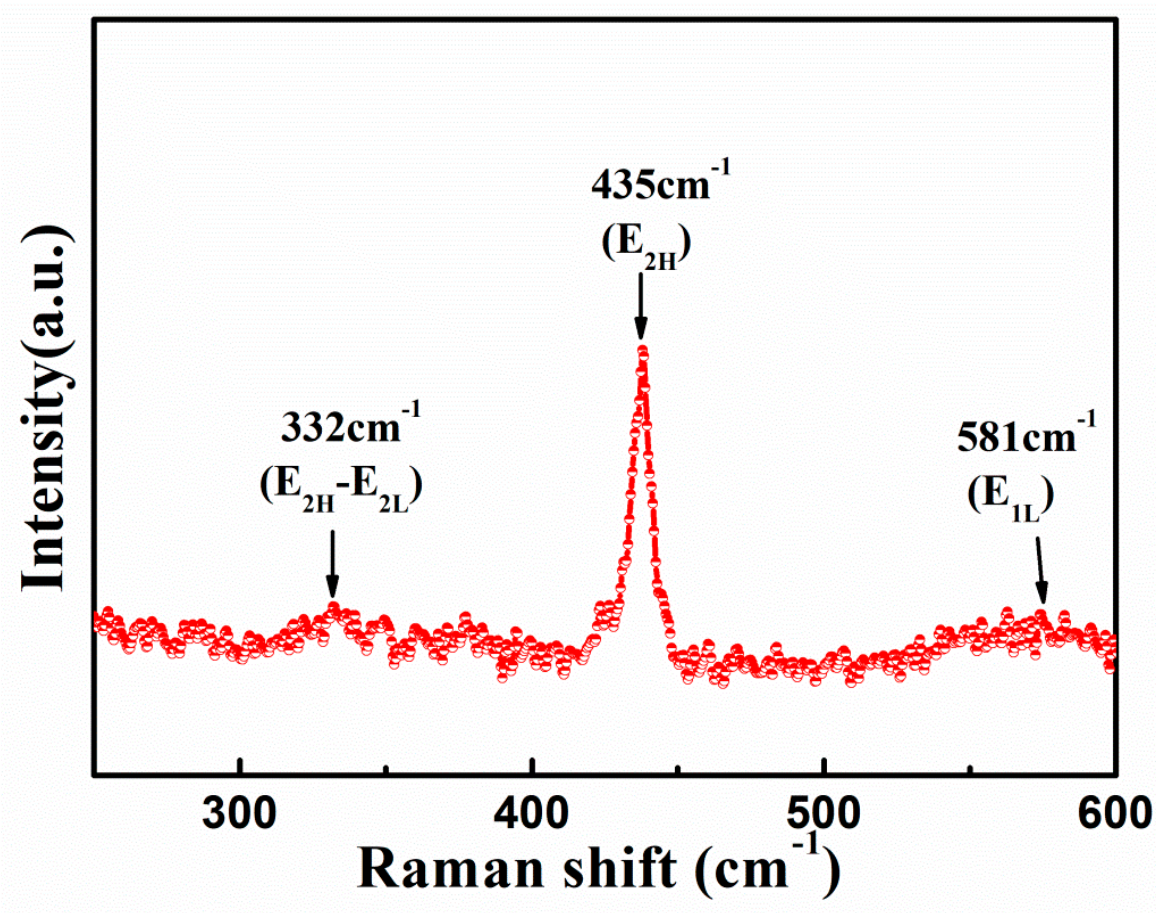

Figure 4. Raman spectrum for $\mathrm{ZnO}$ nanorods recorded at room temperature.

Figure 5 shows the room temperature PL spectrum of the $\mathrm{ZnO}$ nanorods. A high intensity near-band-edge (NBE) emission centered at $\sim 388 \mathrm{~nm}$, and a broad peak at $\sim 507 \mathrm{~nm}$ (green light) corresponds to deep level emission (DLE) were appeared. The free excitons of $\mathrm{ZnO}$ recombined and resulted to the origin of NBE emission, while the photo-originated hole recombination with the defects that were generated green light emission $[39,40]$. Moreover, the narrow size of full-width at half-maximum (FWHM) of the NBE reveals that ZnO nanorods possess excellent crystalline quality, which further confirms the FESEM study.

Figure 6a reveals the cyclic voltammograms $(\mathrm{CV})$ of $\mathrm{ZnO}$ nanorods electrodes in aqueous electrolyte containing $2 \mathrm{M} \mathrm{KOH}$ and recorded with various scan rates of 20,50, 100, and $200 \mathrm{mV} \mathrm{s}^{-1}$ in the potential window of -1.6 to $+1.0 \mathrm{~V}$ vs. $\mathrm{Ag} / \mathrm{AgCl}$. It can be clearly seen from $\mathrm{CV}$ plot in Figure $6 \mathrm{a}$ that by increasing scan rate, the current increases, which depicts the capacitance behavior of the $\mathrm{ZnO}$ 
nanorods. Additionally, as seen in Figure 6a, the CV curves exhibit redox peaks confirming the Faradic nature of the $\mathrm{ZnO}$. The value of specific capacitance of $\mathrm{ZnO}$ nanorods electrodes obtained from $\mathrm{CV}$ curves was found to be $\sim 394 \mathrm{~F} \mathrm{~g}^{-1}$ at $20 \mathrm{mV} \mathrm{s}^{-1}$ scan rate. It was observed that, with increasing in scan rates, the value of capacitance tends to decrease, as shown in Figure $6 \mathrm{~b}$. The number of active ions contributed during the redox reaction is the highest in lower scan rates, while it decreased in higher scan rates. In order to make $\mathrm{Al}$ substrate stable in $\mathrm{KOH}$ electrolyte, on one side of the Al substrate, $\mathrm{ZnO}$ was deposited, however, on the other side of Al substrate, a scotch tape layer was used to cover and protect it from being reacted with $\mathrm{KOH}$ solution which makes the Al substrate stable in $\mathrm{KOH}$. A CV plot of bare Al substrate (covered with scotch tape on both sides) performed at a scan rate of $20 \mathrm{mV} / \mathrm{s}$ is shown in Figure S2. In the CV curve, almost negligible redox peaks of bare aluminum substrate, and much smaller current in the range of $\mu \mathrm{A}$ as compared with those of $\mathrm{ZnO}$ nanorods that is in Ampere range, which suggests that the capacitance contribution from the Al substrate is insignificant. Therefore, $\mathrm{ZnO}$ nanorods grown on Al substrate have been successfully served as the high performance asymmetrical supercapacitor electrode.

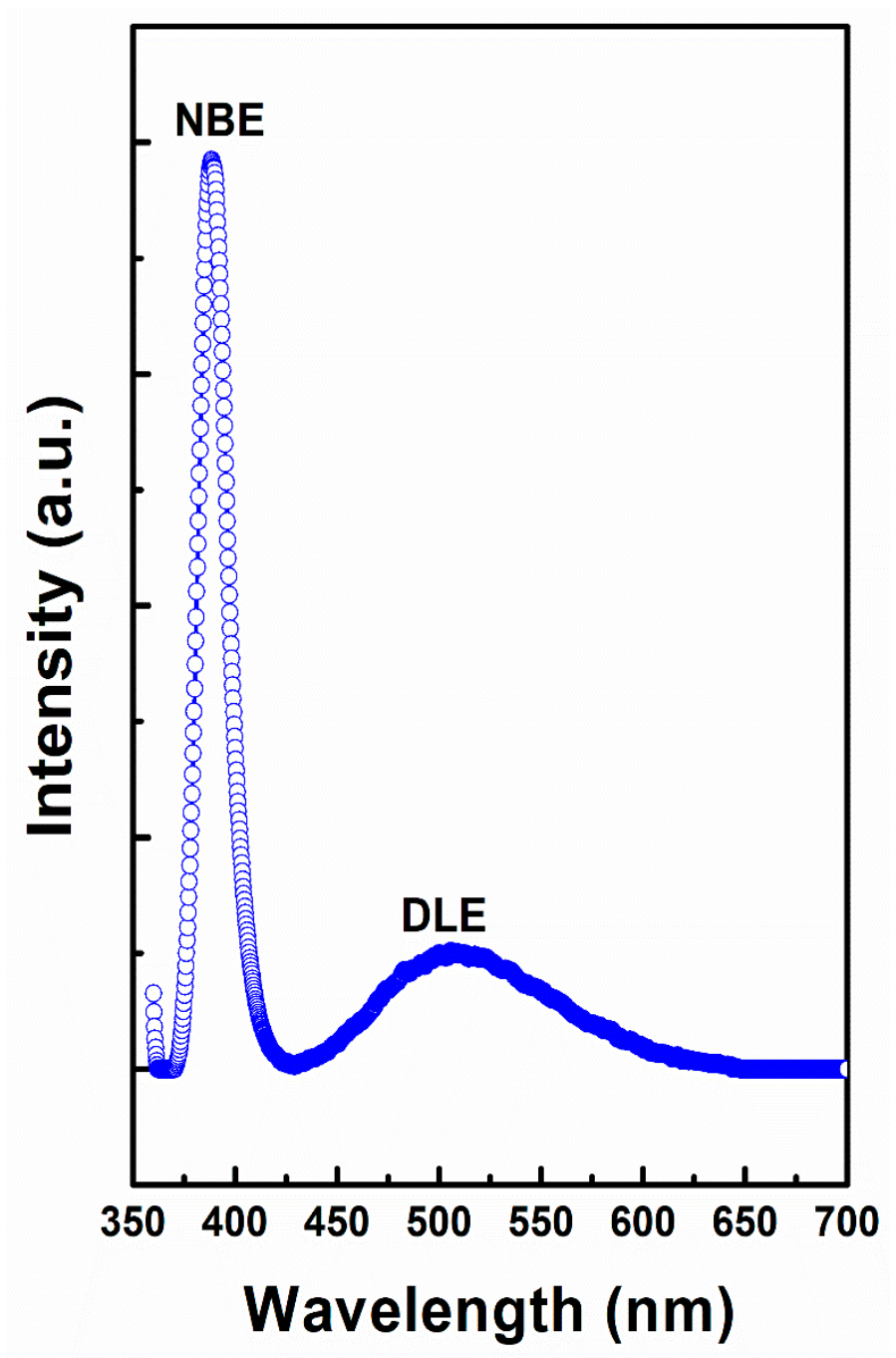

Figure 5. Photoluminescence spectrum of $\mathrm{ZnO}$ nanorods at room temperature.

The charge and discharge characteristics of $\mathrm{ZnO}$ nanorods electrode were further confirmed from galvanostatic charge-discharge (CD) curves that were studied at various current densities ranging from 1to $10 \mathrm{~A} \mathrm{~g}^{-1}$, as shown in Figure 7a. A high specific capacitance obtained from charge and discharge curve was found to be $\sim 332 \mathrm{~F} \mathrm{~g}^{-1}$ at a current density of $1 \mathrm{Ag}^{-1}$ and $\sim 301 \mathrm{Fg}^{-1}$ at $10 \mathrm{Ag}^{-1}$. Figure $7 \mathrm{~b}$ shows the plot of specific capacitance with the change in current density. Interestingly, yet at high 
value of discharge current density of $10 \mathrm{~A} \mathrm{~g}^{-1}$, there is a small reduction in the specific capacitance depicting excellent rate capacitance features of $\mathrm{ZnO}$ nanorods electrode.
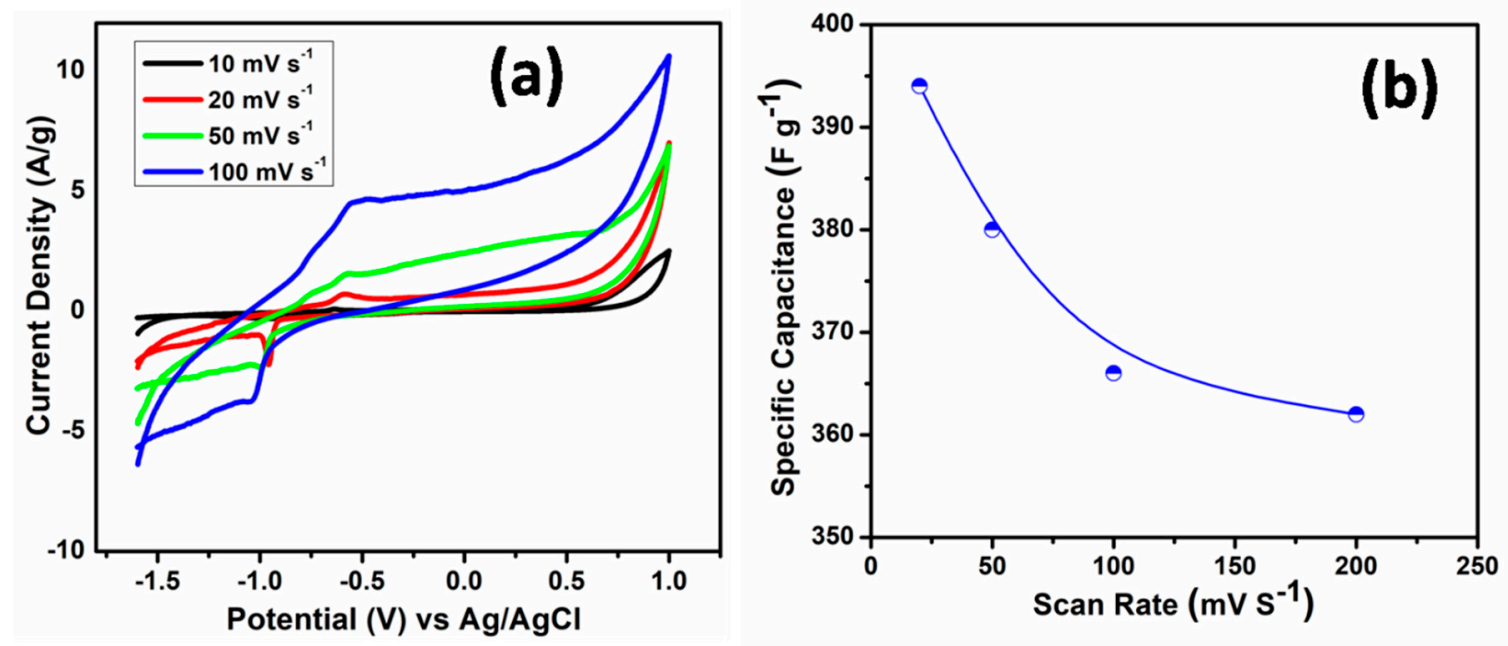

Figure 6. (a) $\mathrm{CVs}$ of $\mathrm{ZnO}$ nanorods electrode at various scan rates with $2 \mathrm{M} \mathrm{KOH}$ electrolyte and $\mathrm{Ag} / \mathrm{AgCl}$ as reference electrode. (b) Variation of specific capacitance of $\mathrm{ZnO}$ nanorods electrode with different scan rate.
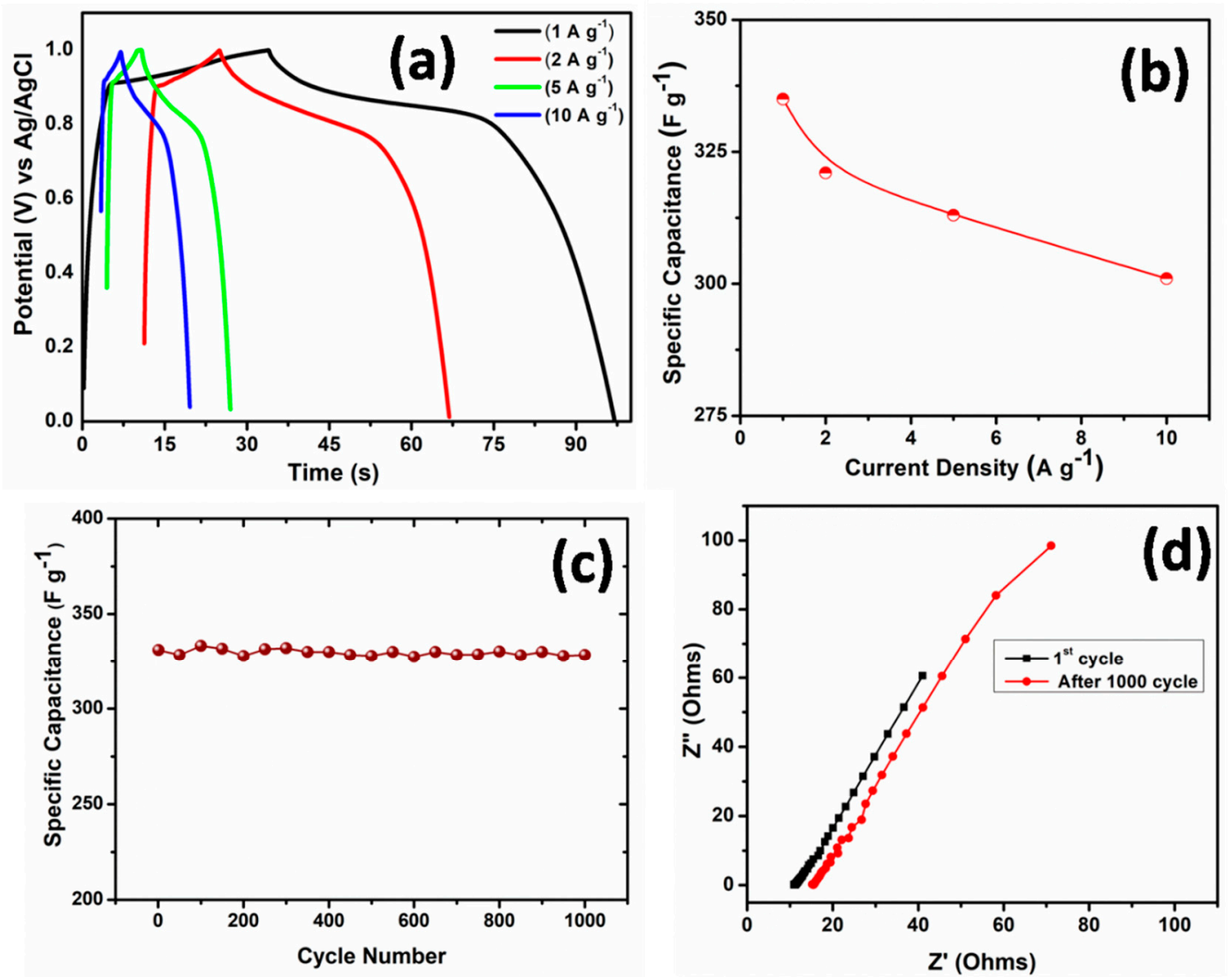

Figure 7. (a) Charge-Discharge curves of $\mathrm{ZnO}$ nanorods electrode based asymmetrical supercapacitor. (b) Variation of specific capacitance of $\mathrm{ZnO}$ nanorods electrode with different current density. (c) Cyclic performance of $\mathrm{ZnO}$ nanorods at a current density of $1 \mathrm{~A} \mathrm{~g}^{-1}$. (d) Nyquist plots of ZnO nanorods electrode for 1st and after 1000th cycle. 
The cycling behavior of the $\mathrm{ZnO}$ electrode was performed for 1000 cycles in order to analyze the cyclic stability of the $\mathrm{ZnO}$ nanorods electrode, as shown in Figure 7c. Long-term cycling of $\mathrm{ZnO}$ nanorods electrode shows no obvious fade, except a very small decrease of $\sim 2 \%$ in the specific capacitance, even after 1000 cycles. These cyclic stability results of $\mathrm{ZnO}$ nanorods on $\mathrm{Al}$ substrate based electrode indicated that minor changes might occur in the physical or chemical structure during the charge discharge cycling procedure. The performance of the $\mathrm{ZnO}$ nanorods electrode in terms of specific capacity $(\mathrm{mAh} / \mathrm{g}$ ) vs. cycle number has been studied and shown in Figure S3. It could be clearly seen from Figure S3 that the specific capacity of $58.33 \mathrm{mAh} / \mathrm{g}$ was observed for the first cycle, which was maintained for 1000 cycles with capacity retention of $\sim 98 \%$.

The highest specific capacitance of $394 \mathrm{~F} \mathrm{~g}^{-1}$ at a scan rate of $20 \mathrm{mVs}^{-1}$ from CV and $332 \mathrm{~F} \mathrm{~g}^{-1}$ from charge-discharge obtained in our work for $\mathrm{ZnO}$ nanorods is superior and highly attractive than that of other $\mathrm{ZnO}$ based electrodes that were reported in the literature (see Table 1). He et al. [24] reported a value of $378.5 \mathrm{~F} \mathrm{~g}^{-1}$ for $\mathrm{ZnO}$ nanocones and $191.5 \mathrm{~F} \mathrm{~g}^{-1}$ for $\mathrm{ZnO}$ NWs. Alver et al. [25] reported specific capacitance of $5.87 \mathrm{~F} \mathrm{~g}^{-1}, 5.35 \mathrm{~F} \mathrm{~g}^{-1}$ and $4.14 \mathrm{~F} \mathrm{~g}^{-1}$ for $\mathrm{ZnO}$ electrodes obtained from nitrate, acetate and chloride precursor solutions, respectively. Luo et al. [26] showed maximum capacitance of $160.4 \mathrm{~F} \mathrm{~g}^{-1}$ for electrodes from $\mathrm{ZnO}$ tetrapods. By comparing our results with carbon nanostructures based electrode without metal oxide, it was observed that a capacitance value of $370 \mathrm{~F} \mathrm{~g}^{-1}$ at $1 \mathrm{~A} \mathrm{~g}^{-1}$ in $6 \mathrm{M} \mathrm{NaOH}$ for graphene, as reported by Xiao et al. [9], is lower than that of the specific capacitance $\left(394 \mathrm{~F} \mathrm{~g}^{-1}\right.$ ) of our $\mathrm{ZnO}$ electrode. Additionally, the performance of our $\mathrm{ZnO}$ nanorods supercapacitors electrode is much better than the transition metal oxides, sulfides, and $\mathrm{ZnO}$ based nanocomposites reported earlier [41-45] (see Table 1). In our work, the enhanced performance of $\mathrm{ZnO}$ nanorods might be ascribed to the structural advantages of the $\mathrm{ZnO}$ on $\mathrm{Al}$ substrate assisted prepared electrode.

Table 1. A comparative study of specific capacitance between current work and earlier reports.

\begin{tabular}{cccc}
\hline Electrode Material & Scan Rate $\left(\mathbf{m V ~ s}^{\mathbf{- 1}}\right)$ & Specific Capacitance $\left(\mathbf{F ~}^{\mathbf{- 1}}\right)$ & Ref. \\
\hline ZnO nanocones & 20 & 377.4 & {$[24]$} \\
ZnO nanostructures & 5 & 5.87 & {$[25]$} \\
ZnO tetrapods & 10 & 160.4 & {$[26]$} \\
$\mathrm{ZnO}$ coated with $\mathrm{MnO}_{2}$ & 25 & 222 & {$[16]$} \\
$\mathrm{ZnO} / \mathrm{RGO}$ & 5 & 322.1 & {$[41]$} \\
$\mathrm{CeO}_{2} / \mathrm{Fe}_{2} \mathrm{O}_{3}$ nanospindles & 5 & 142.6 & {$[42]$} \\
$\mathrm{MoS}_{2}$ on Mo foil & 5 & 197.1 & {$[43]$} \\
CoMoO & 98.34 & {$[44]$} \\
ZnS/graphene & 5 & 197.1 & {$[45]$} \\
$\mathrm{ZnO}$ nanorods on Al substrate & 5 & 394.1 & This work \\
\hline
\end{tabular}

Electrochemical impedance spectroscopy (EIS) was used to further study the electrochemical characteristics of the $\mathrm{ZnO}$ nanorods electrode/electrolyte interface. Figure $7 \mathrm{~d}$ depicts the typical Nyquist plots of $\mathrm{ZnO}$ nanorods electrodes before and after cycling test. In high frequency region, the $\mathrm{x}$-intercept of the Nyquist curve reflects the equivalent series resistance (ESR), which results from the origin of resistance from various sources, such as the electrolyte, internal resistance of electrode material, and the interface resistance [46]. While, the diameter of the semicircle attributes to the resistance of charge transfer on the surface of the electrode (Rct) $[47,48]$. The value of ESR of $\mathrm{ZnO}$ nanorods electrode before cycling test was measured to be $8.1 \Omega$, and after 1000 cycles, a little increase in the ESR value of about $12.4 \Omega$ was observed, as shown in Figure $7 \mathrm{~d}$. This smaller resistance and its minute change even after 1000 cycles might be due to the enhanced contact of the electrode material with the electrolyte. Interestingly, in the Nyquist plot, there was no distinct semicircle observed, which further indicated that $\mathrm{ZnO}$ nanorods electrodes exhibit excellent capacitive behavior [49]. 


\section{Conclusions}

In summary, $\mathrm{ZnO}$ nanorods on $\mathrm{Al}$ substrate as electrode for supercapacitors have been successfully grown at low temperature of $80^{\circ} \mathrm{C}$ while using a facile wet chemical route with excellent electrochemical performance. As grown $\mathrm{ZnO}$ nanorods possessed high crystallinity and growth direction along the c-axis which are in close agreement with the HRTEM and SAED results. The FESEM results demonstrate well-defined hexagonal shape of $\mathrm{ZnO}$ nanorods homogeneously grown on Al substrate. Raman studies show that a high intensity $\mathrm{E}_{2 \mathrm{H}}$ mode of the wurtzite lattice is evidenced in addition to the low intensity broad peaks of other modes. The PL spectrum demonstrates a strong NBE emission positioned at $\sim 388 \mathrm{~nm}$ and a broad DLE emission at $\sim 507 \mathrm{~nm}$. The electrochemical studies demonstrate that the grown $\mathrm{ZnO}$ nanorods electrode exhibit superior performance with the specific capacitance of $394 \mathrm{~F} \mathrm{~g}^{-1}$ at $20 \mathrm{mV} \mathrm{s}^{-1}$ scan rate and high cyclic efficiencies of $>98 \%$ after 1000 cycles; thus, it could be considered to bea potential candidate of electrode for supercapacitors. The presented simple and cost effective approach for large scale production of $\mathrm{ZnO}$ nanorods on $\mathrm{Al}$ substrate is highly attractive and might be applicable for the development of future binder-free metal oxide electrodes for supercapacitors.

Supplementary Materials: The following are available online at http://www.mdpi.com/2079-4991/10/10/1979/s1, Figure S1: XRD pattern of Al substrate used in the present work., Figure S2: CV plot of bare Al substrate (covered with scotch tape) in 2M KOH electrolyte, Figure S3: Plot of Specific capacity vs cycle number for ZnO nanorods electrode at current density of $1 \mathrm{~A} / \mathrm{g}$, Table S1: Comparison of $\mathrm{ZnO}$ grown on $\mathrm{Al}$ and $\mathrm{Al}_{2} \mathrm{O}_{3}$ substrate.

Author Contributions: Conceptualization, F.A.; Data curation, N.A. (Nishat Arshi); Formal analysis, S.K.; Funding acquisition, S.G.H.; Resources, N.A. (Naushad Ahmad); Visualization, A.A.; Writing-original draft, F.A.; Writing-review \& editing, G.A., B.A., N.A. (Nishat Arshi), S.G.H., A.U. and A.A. All authors have read and agreed to the published version of the manuscript.

Funding: This research was funded by King Abdulaziz City for Science and Technology (KACST) for supporting this research by project number 10-NAN1144-06.

Acknowledgments: The authors would like to thank the King Abdulaziz City for Science and Technology (KACST) for supporting this research by project number 10-NAN1144-06.

Conflicts of Interest: The authors declare that they have no competing interest.

\section{References}

1. Shao, Y.L.; El-Kady, M.F.; Wang, L.J.; Zhang, Q.H.; Li, Y.G.; Wang, H.Z.; Mousavi, M.F.; Kaner, R.B. Graphene-based materials for flexible supercapacitors. Chem. Soc. Rev. 2015, 44, 3639-3665. [CrossRef] [PubMed]

2. Zhong, C.; Deng, Y.D.; Hu, W.B.; Qiao, J.L.; Zhang, L.; Zhang, J.J. A review of electrolyte materials and compositions for electrochemical supercapacitors. Chem. Soc. Rev. 2015, 44, 7484-7539. [CrossRef] [PubMed]

3. Liang, J.; Zhu, G.; Lu, Z.; Zhao, P.; Wang, C.; Ma, Y.; Xu, Z.; Wang, Y.; Hu, Y.; Ma, L.; et al. Integrated perovskite solar capacitors with high energy conversion efficiency and fast photo-charging rate. J. Mater. Chem. A 2018, 6, 2047-2052. [CrossRef]

4. Simon, P.; Gogotsi, Y. Materials for electrochemical capacitors. Nat. Mater. 2008, 7, 845-854. [CrossRef]

5. Bagheri, N.; Aghaei, A.; Ghotbi, M.Y.; Marzbanrad, E.; Vlachopoulos, N.; Häggman, L.; Wang, M.; Boschloo, G.; Hagfeldt, A.; Skunik-Nuckowska, M.; et al. Combination of asymmetric supercapacitor utilizing activated carbon and nickel oxide with cobalt polypyridyl-based dye-sensitized solar cell. Electrochim. Acta 2014, 143, 390-397. [CrossRef]

6. Navarrete-Astorga, E.; Rodr'́1guez-Moreno, J.; Dalchiele, E.A.; Schrebler, R.; Leyton, P.; Ramos-Barrado, J.R.; Martín, F. A transparent solid-state ion gel for supercapacitor device applications. J. Solid State Electrochem. 2017, 21, 1431-1444. [CrossRef]

7. Rodríguez-Moreno, J.; Navarrete-Astorga, E.; Dalchiele, E.A.; Sánchez, L.; Ramos-Barrado, J.R.; Martín, F. Polyvinylpyrrolidone- $\mathrm{LiClO}_{4}$ solid polymer electrolyte and its application in transparent thin film supercapacitors. J. Power Sources 2013, 237, 270-276. [CrossRef] 
8. Rodríguez-Moreno, J.; Navarrete-Astorga, E.; Dalchiele, E.A.; Schrebler, R.; Ramos-Barrado, J.R.; Martín, F. Vertically aligned ZnO@CuS@PEDOTcore@shellnanorod arrays decorated with $\mathrm{MnO}_{2}$ nanoparticles for a high-performance and semi-transparent supercapacitor electrode. Chem. Commun. 2014, 5652, 5652-5655. [CrossRef]

9. Xiao, N.; Tan, H.; Zhu, J.; Tan, L.; Rui, X.; Dong, X.; Yan, Q. High-Performance Supercapacitor Electrodes Based on Graphene Achieved by Thermal Treatment with the Aid of Nitric Acid. ACS Appl. Mater. Interface 2013, 5, 9656. [CrossRef]

10. Hu, C.C.; Chang, K.H.; Lin, M.C.; Wu, Y.T. Design and tailoring of the nanotubular arrayed architecture of hydrous $\mathrm{RuO}_{2}$ for next generation supercapacitors. Nano Lett. 2006, 6, 2690-2695. [CrossRef]

11. Hung, C.J.; Hung, J.H.; Lin, P.; Tseng, T.Y. Electrophoretic fabrication and characterizations of manganese oxide/carbon nanotube nanocomposite pseudocapacitors. J. Electrochem. Soc. 2011, 158, A942-A947. [CrossRef]

12. Chen, Z.; Augustyn, V.; Wen, J.; Zhang, Y.; Shen, M.; Dunn, B.; Lu, Y. High-performance supercapacitors based on intertwined $\mathrm{CNT} / \mathrm{V}_{2} \mathrm{O}_{5}$ nanowire nanocomposites. Adv. Mater. 2011, 23, 791-795. [CrossRef] [PubMed]

13. Kalpana, D.; Omkumar, K.S.; Kumar, S.S.; Renganathan, N.G. A novel high power symmetric ZnO/carbon aerogel composite electrode for electrochemical supercapacitor. Electrochim. Acta 2006, 52, 1309-1315. [CrossRef]

14. Kim, I.H.; Kim, K.B. Electrochemical characterization of hydrous ruthenium oxide thin-film electrodes for electrochemical capacitor applications. J. Electrochem. Soc. 2006, 153, A383-A389. [CrossRef]

15. Li, X.; Wang, Z.; Qiu, Y.; Pan, Q.; Hu, P.A. 3D Graphene/ZnONanorods Composite Networks as Supercapacitor Electrodes. J. Alloys Compd. 2015, 620, 31-37. [CrossRef]

16. Huang, G.; Zhang, W.; Xu, S.; Li, Y.; Yang, Y. MicrosphericalZnO Synthesized from a Metal-Organic Precursor for Supercapacitors. Ionics 2016, 22, 2169-2174. [CrossRef]

17. Chen, H.C.; Lyu, Y.R.; Fang, A.; Lee, G.J.; Karuppasamy, L.; Wu, J.J.; Lin, C.K.; Anandan, S.; Chen, C.Y. The Design of ZnONanorod Arrays Coated with MnOx for High Electrochemical Stability of a Pseudocapacitor Electrode. Nanomaterials 2020, 10, 475. [CrossRef]

18. Gao, J.W.Z.; Li, Z.; Wang, B.; Yan, Y.; Liu, Q.; Mann, T.; Zhang, M.; Jiang, Z. Green synthesis of graphene nanosheets/ZnO composites and electrochemical properties. J Solid State Chem. 2011, 184, 1421-1427.

19. Lu, T.; Pan, L.; Li, H.; Zhu, G.; Lv, T.; Liu, X.; Sun, Z.; Chen, T.; Chua, D.H. Microwave-assisted synthesis of graphene-ZnO nanocomposites for electrochemical supercapacitors. J. Alloy Compd. 2011, 509, 5488-5492. [CrossRef]

20. Zhang, Y.; Sun, X.; Pan, L. Carbon nanotube-ZnO nanocomposite electrodes for supercapacitors. Solid State Ion. 2009, 180, 1525-1528. [CrossRef]

21. Zhang, Y.; Li, H.; Lu, T. Capacitive behavior of graphene-ZnO composite film for supercapacitors. J. Electroanal. Chem. 2009, 634,68-71. [CrossRef]

22. Jayalakshmi, M.; Palaniappa, M.; Balasubramanian, K. Single step solution combustion synthesis of $\mathrm{ZnO} /$ carbon composite and its electrochemical characterization for supercapacitor application. Int. J. Electrochem. Sci. 2008, 3, 96-103.

23. Kim, C.H.; Kim, B.H. Zinc oxide/activated carbon nanofiber composites for high-performance supercapacitor electrodes. J. Power Sources 2015, 274, 512-520. [CrossRef]

24. He, X.; Yoo, J.E.; Lee, M.H.; Bae, J. Morphology Engineering of ZnO Nanostructures for High Performance Supercapacitors: Enhanced Electrochemistry of ZnONanocones Compared to ZnO Nanowires. Nanotechnology 2017, 28, 245402-245421. [CrossRef]

25. Alver, Ü.; Tanrıverdi, A.; Akgül, Ö. Hydrothermal Preparation of ZnO Electrodes Synthesized from Different Precursors for Electrochemical Supercapacitors. Synth. Met. 2016, 211, 30-34. [CrossRef]

26. Luo, Q.; Xu, P.; Qiu, Y.; Cheng, Z.; Chang, X.; Fan, H. Synthesis of ZnO Tetrapods for High-Performance Supercapacitor Applications. Mater. Lett. 2017, 198, 192-195. [CrossRef]

27. Fu, Z.W.; Feng, H.; Ye, Z.; Yue, C.; Qin, Q.Z. The electrochemical reaction of zinc oxide thin films with lithium. J. Electrochem. Soc. 2003, 150, A714-A720. [CrossRef]

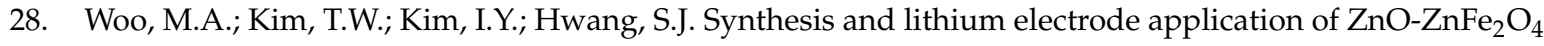
nanocomposites and porously assembled $\mathrm{ZnFe}_{2} \mathrm{O}_{4}$ nanoparticles. Solid State Ion. 2011, 182, 91-97. [CrossRef]

29. Park, K.T.; Xia, F.; Kim, S.W.; Kim, S.B.; Song, T.; Paik, U.; Park, W.I. Facile synthesis of ultrathin ZnO nanotubes with wellorganized hexagonal nanowalls and sealed layouts: Applications for lithium ion battery anodes. J. Phys. Chem. C 2013, 117, 1037-1043. [CrossRef] 
30. Greene, L.E.; Law, M.; Tan, D.H.; Montano, M.; Goldberger, J.; Somorjai, G.; Yang, P.D. General Route to Vertical ZnO Nanowire Arrays Using Textured ZnO Seeds. Nano Lett. 2005, 5, 1231-1236. [CrossRef]

31. Wang, Y.Y.; Jiang, X.J.; Yang, L.S.; Jia, N.; Ding, Y. In situ synthesis of C/Cu/ZnO porous hybrids as anode materials for lithium ion batteries. ACS Appl. Mater. Interfaces 2014, 6, 1525-1532. [CrossRef] [PubMed]

32. Chen, J.; Liu, Y.; Li, W.; Yang, H.; Xu, L. The large electrochemical capacitance of nitrogen doped mesoporous carbon derived from egg white by using a ZnO template. RSC Adv. 2015, 5, 98177. [CrossRef]

33. You, J.B.; Zhang, X.W.; Dong, J.J.; Song, X.M.; Yin, Z.G.; Chen, N.F.; Yan, H. Localized-Surface-Plasmon Enhanced the $357 \mathrm{~nm}$ Forward Emission from ZnMgO Films Capped by Pt Nanoparticles. Nanoscale Res. Lett. 2009, 4, 1121. [CrossRef] [PubMed]

34. Yang, W.; Wang, F.; Guan, Z.; He, P.; Liu, Z.; Hu, L.; Chen, M.; Zhang, C.; He, X.; Fu, Y. Comparative Study of ZnO Thin Films Grown on Quartz Glass and Sapphire (001) Substrates by Means of Magnetron Sputtering and High-Temperature Annealing. Appl. Sci. 2019, 9, 4509. [CrossRef]

35. Gaddama, V.; Neellaa, N.; Nayakb, M.M.; Rajannaa, K. Al:ZnONanosheets on Flexible Stainless Steel Substrate as Impact Sensor. Mater. Today Proc. 2018, 5, 10779. [CrossRef]

36. Zhao, S.H.; Guo, J.X.; Jiang, F.; Su, Q.M.; Zhang, J.; Du, G.H. Growth of hierarchal porous CoO nanowire arrays on carbon cloth as binder-free anodes for high-performance flexible lithium-ion batteries. J. Alloys Compd. 2016, 655, 372. [CrossRef]

37. Arguello, C.A.; Rousseau, D.L.; Porto, S.P.S. First-order Raman effect in wurtzite-type crystals. Phys. Rev. 1969, 181, 1351. [CrossRef]

38. Damen, T.C.; Porto, S.P.S.; Tell, B. Raman effect in zinc oxide. Phys. Rev. 1966, 142, 570. [CrossRef]

39. Huang, M.H.; Wu, Y.; Feick, H.; Tran, N.; Weber, E.; Yang, P. Catalytic growth of zinc oxide nanowires by vapor transport. Adv. Mater. 2001, 13, 113. [CrossRef]

40. Hung, C.H.; Whang, W.T. A novel low-temperature growth and characterization of single crystal ZnO nanorods. Mater. Chem. Phys. 2003, 82, 705-710. [CrossRef]

41. Hwang, Y.H.; Lee, S.M.; Kim, Y.J.; Kahng, Y.H.; Lee, K. A new approach of structural and chemical modification on graphene electrodes for high-performance supercapacitors. Carbon 2016, 100, 7-15. [CrossRef]

42. Arul, N.S.; Mangalaraj, D.; Ramachandran, R.; Grace, A.N.; Han, J.I. Fabrication of $\mathrm{CeO}_{2} / \mathrm{Fe}_{2} \mathrm{O}_{3}$ composite nanospindles for enchancedvisble light driven photocatalysts and supercapacitor electrodes. J. Mater. Chem. A 2015, 3, 15248. [CrossRef]

43. Krishnamoorthy, K.; Veerasubramani, G.K.; Pazhamalai, P.; Kim, S.J. Designing two dimensional nanoarchitectured $\mathrm{MoS}_{2}$ sheets grown on Mo foil as a binder free electrode for supercapacitors. Electrochim. Acta 2016, 190, 305-312. [CrossRef]

44. GVeerasubramani, K.; Krishnamoorthy, K.; Kim, S.J. Electrochemical performance of an asymmetric supercapacitor based on graphene and cobalt molybdate electrodes. RSC Adv. 2015, 5, 16319. [CrossRef]

45. Ramachandran, R.; Saranya, M.; Kollu, P.; Raghupathy, B.P.C.; Jeong, S.K.; Gracem, A.N. Solvothermal synthesis of zinc sulfide decorated graphene $(\mathrm{ZnS} / \mathrm{G})$ nanocomposites for novel supercapacitor electrodes. Electrochim. Acta 2015, 178, 647-657. [CrossRef]

46. Zhang, J.; Kong, L.B.; Cai, J.J.; Luo, Y.C.; Kang, L. Nanoflake-like cobalt hydroxide/ ordered mesoporous carbon composite for electrochemical capacitors. J. Solid State Electrochem. 2010, 14, 2065-2075. [CrossRef]

47. Shi, S.; Zhuang, X.; Chen, B.; Wang, X. Solution blowig of ZnO nanoflake-encapsulated carbon nanofibers as electrodes for supercapacitors. J. Mater. Chem. A 2013, 1, 13779. [CrossRef]

48. Zhang, X.; Wang, X.; Jiang, L.; Wu, H.; Wu, C.; Su, J. Effect of aqueous electrolytes on the electrochemical behaviors of supercapacitors based on hierarchically porous carbons. J. Power Sources 2012, 216, 290-296. [CrossRef]

49. Niu, H.; Zhou, D.; Yang, X.; Li, X.; Wang, Q.; Qu, F.Y. Towards three-dimensional hierarchical ZnO nanofiber@Ni $(\mathrm{OH})_{2}$ nanoflake core-shell heterostructures for high performance asymmetric supercapacitors. J. Mater. Chem. A 2015, 3, 18413-18421. [CrossRef]

(C) 2020 by the authors. Licensee MDPI, Basel, Switzerland. This article is an open access article distributed under the terms and conditions of the Creative Commons Attribution (CC BY) license (http://creativecommons.org/licenses/by/4.0/). 